\title{
The optimal timing and courses of bevacizumab added to chemotherapy for non-squamous non-small cell lung cancer: revelations from the real-world experience in a single Chinese cancer center
}

\author{
Qianqian Long ${ }^{1,2,3 \#}$, Yu Feng ${ }^{1,2,3 \#}$, Chang Liu ${ }^{1,2,3 \#}$, Xianghua $W_{u^{1,2,3}}$, Huijie Wang ${ }^{1,2,3}$, Hui Yu ${ }^{1,2,3}$, \\ Xinmin Zhao ${ }^{1,2,3}$, Jialei Wang ${ }^{1,2,3}$
}

${ }^{1}$ Department of Medical Oncology, Fudan University Shanghai Cancer Center, Shanghai, China; ${ }^{2}$ Department of Oncology, Shanghai Medical College, Fudan University, Shanghai, China; ${ }^{3}$ Institute of Thoracic Oncology, Fudan University, Shanghai, China

Contributions: (I) Conception and design: J Wang, X Zhao; (II) Administrative support: X Wu, H Wang, H Yu; (III) Provision of study materials or patients: Y Feng, C Liu, Q Long; (IV) Collection and assembly of data: Q Long, Y Feng, C Liu, X Zhao, J Wang; (V) Data analysis and interpretation: Q Long, Y Feng, C Liu, X Zhao, J Wang; (VI) Manuscript writing: All authors; (VII) Final approval of manuscript: All authors.

"These authors contributed equally to this work.

Correspondence to: Xinmin Zhao; Jialei Wang. Department of Medical Oncology, Fudan University Shanghai Cancer Center, No. 270 Dong An Road, Shanghai, China; Department of Oncology, Shanghai Medical College, Fudan University, No. 138 Yi Xue Yuan Road, Shanghai, China.

Email: mizuyiaaa@163.com; m18017312369@163.com.

Background: Bevacizumab combined with platinum-based chemotherapy has been approved in the firstline treatment for advanced non-squamous non-small cell lung cancer (NSCLC) without driver genes, but this regimen for second-line or later-line treatment of non-squamous NSCLC remains to be further tested. Our study aimed to provide data on the safety and effectiveness of bevacizumab (Bev)-containing chemotherapy in different-line settings for patients with NSCLC in the Chinese real-world clinical routine practice and to explore predictors for progression-free survival (PFS) and overall survival (OS).

Methods: We reviewed the medical records of 194 patients with non-squamous NSCLC who received Bev plus chemotherapy as the first-, second- or third- or later-line treatment between December 2009 and January 2020 at Fudan University, Shanghai Cancer Center. Clinical characteristics, treatment history, clinical evaluation, and adverse effects of each patient were deeply analyzed. PFS and OS were estimated by the Kaplan-Meier method. Univariate and multivariate analyses were conducted to find predictors of longer PFS and OS.

Results: One hundred ninety-four patients were enrolled in this study, including 102 (52.6\%), 58 (29.9\%) and $34(17.5 \%)$ patients received Bev in combination with the first-line chemotherapy $(\mathrm{Bev}+\mathrm{Che} 1)$, second-line chemotherapy (Bev + Che2) and third-/later-line chemotherapy (Bev + Che3), respectively. Administration of Bev in combination with the first-line chemotherapy and $>6$ courses were independent predictors of significantly prolonged PFS. Whereas, patients older than 65 years or with ECOG PS $\geq 2$ may not benefit more from Bev added to the first-line chemotherapy compared to second-/later-line chemotherapy. PFS of patients received treatment with/without chemotherapy as maintenance therapy showed no significant difference $(\mathrm{P}=0.354)$ in $>6$ courses Bev cohort. As for OS, Bev plus the first-line chemotherapy and number of metastatic sites $<3$ were independent predictors. The most common adverse effects (AE) were leukopenia, neutropenia, hypertension, and proteinuria. Twenty patients suffered from AE $\geq$ Grade 3 .

Conclusions: Bev, in combination with the front-line chemotherapy, is proven beneficial for survival welltolerated.

Keywords: Non-small cell lung cancer (NSCLC); bevacizumab (Bev); chemotherapy; predictor 
Submitted Aug 13, 2020. Accepted for publication Oct 13, 2020.

doi: $10.21037 /$ atm-20-6327

View this article at: http://dx.doi.org/10.21037/atm-20-6327

\section{Introduction}

Lung cancer is the most common cause of cancer-related mortality worldwide, among which non-small-cell lung cancer (NSCLC) accounts for $80-85 \%$ of all lung cancer (1). Since most of the lung cancer is diagnosed at an advanced or unresectable stage, the identification of an efficient therapeutic strategy for these patients is still a significant challenge for oncologists. In the past decade, the administration of tyrosine kinase inhibitors (TKIs) and immune checkpoint inhibitors significantly improved the survival of patients with predictive biomarkers, but most patients harbor no druggable genomic alterations (2-5). For patients who cannot benefit from targeted therapies, chemotherapy-dominant treatment is still the primary therapeutic strategy.

Given that tumor angiogenesis remains a critical step for tumorigenesis (6), angiogenesis inhibition is considered another promising therapeutic strategy for patients with NSCLC. As a crucial molecular regulator in stimulating angiogenesis, vascular endothelial growth factor (VEGF) has been identified playing essential roles in the progression of cancer $(7,8)$. As a recombinant humanized monoclonal antibody that blocks VEGF, the US Food and Drug Administration has approved bevacizumab (FDA) in 2006 to combine with platinum-based chemotherapy for metastatic non-squamous NSCLC in the firstline treatment. ECOG4599, AVAil, SAiL, ARIES, and BEYOND studies showed bevacizumab combined with chemotherapy significantly improved the objective response rate (ORR), progression-free survival (PFS) and overall survival (OS) compared to chemotherapy monotherapy in non-squamous NSCLC (9-13). To date, bevacizumab, in combination with platinum-based chemotherapy, has been recommended as the first-line therapy for advanced nonsquamous NSCLC without driver genes. In the secondline setting, bevacizumab, in combination with single-agent chemotherapy, achieved improved ORR and a tendency of prolonged PFS compared with single-agent alone, while no OS benefit was observed (14). In the third-line setting, improved ORR, disease control rate (DCR), and PFS with bevacizumab-containing chemotherapy compared with chemotherapy alone were also observed (15). However, whether bevacizumab administration at first or later line affects the survival outcomes is still unclear. So far, few studies focused on predictors affecting clinical outcomes of Chinese patients receiving bevacizumab (Bev)-containing regimens. And the influence of driver gene status and the course of treatment on Bev therapy efficiency is still worth exploring.

Our study aimed to further investigate the efficacy and safety of bevacizumab plus chemotherapy compared with chemotherapy alone in different-line settings for lung adenocarcinoma patients in Chinese real-world clinical routine practice, as well as to explore prognostic factors for PFS and OS data.

We present the following article in accordance with the STROBE reporting checklist (available at http://dx.doi. org/10.21037/atm-20-6327).

\section{Methods}

\section{Patients}

We reviewed the medical records of two hundred and thirtyeight patients with lung adenocarcinoma who received $\geq 2$ courses of bevacizumab plus chemotherapy treatment between December 2009 and January 2020 at Fudan University Shanghai Cancer Center. Twenty-eight patients with an early loss to follow-up, ten patients without detailed medical records, and six patients received bevacizumab plus chemotherapy in cross-line settings were excluded. Hence, 194 patients were collected for our retrospective study, including 102 (52.6\%), 58 (29.9\%) and 34 (17.5\%) patients received Bev plus chemotherapy at the first-line chemotherapy (Bev + Che1), second-line chemotherapy (Bev + Che2) and third-/later-line chemotherapy (Bev + Che3), respectively.

Data were cut off at the last follow-up (4/20/2020). Patients alive at the cut-off date were censored. All procedures performed in this study involving human participants were in accordance with the Declaration of Helsinki (as revised in 2013). The institutional review board approved this study of the Fudan University of Shanghai Cancer Center. Individual consent for this retrospective analysis was waived. 


\section{Clinical definitions}

Patients were staged according to the 8th edition of the American Joint Committee on Cancer (AJCC) classification. The tumor response was assessed every two courses of bevacizumab therapy according to the Response Evaluation Criteria in Solid Tumors (RECIST version 1.1) guideline. Disease control rate (DCR) was defined as the percentage of patients with complete response (CR), partial response (PR), and stable disease $(\mathrm{SD})$. Objective response rate (ORR) was defined as the percentage of patients with CR and PR. PFS was defined as the time from initiation of Bev to the first disease progression or death. OS was defined as the time from initiation of the first-line treatment to death because of any cause.

\section{Statistical analysis}

Data on patient baseline characteristics, tumor response, and safety were summarized by frequency and percentage for categorical variables and by medians and ranges for continuous variables. PFS and OS were estimated by the Kaplan-Meier method, along with $95 \%$ confidence intervals (CIs).

Differences between DCR and ORR of the distinct groups were assessed using Pearson's $\chi^{2}$ or Fisher's exact test. Univariate analyses of PFS and OS were performed with a log-rank test. Followed by the test of proportional hazard assumption, variables with $\mathrm{P}$ value less than 0.1 in the univariate analysis were included in a multivariate analysis to identify the independent predictors. The hazard ratio (HR) and related $95 \%$ CI were analyzed using Cox multivariate proportional hazard model.

The significance level $(\alpha)$ of statistical tests was set at $\mathrm{P}<0.05$. While pairwise comparisons were involved, adjusted awas calculated with Bonferroni correction. All expressed P values, and CIs were two-tailed. All statistical analyses were conducted using IBM $^{\circledR}$ SPSS ${ }^{\circledR}$ Statistics version 24.

\section{Effectiveness and safety evaluation}

Adverse events (AEs) were assessed monthly, according to the National Cancer Institute's Common Terminology Criteria for Adverse Events (CTCAE), version 4.0.

\section{Results}

\section{Patient baseline characteristics}

One hundred ninety-four patients were eventually enrolled in this study, among which 102102 (52.6\%) and 92 (47.4\%) patients were treated with Bev at the first-line chemotherapy (Bev + Che1) and second-/third-/later-line chemotherapy (Bev + Che2/3), respectively (Table 1). Most patients harbored stage IV cancer, which metastasized to lung, bone, pleura, brain, liver, and adrenal gland. The most often mutated driver genes were EGFR in both Bev + Che1 (31.4\%) and Bev + Che2/3 groups (48.9\%). Most patients received platinum-based double regimens as concomitant chemotherapy (97/102, 78/92 in Bev + Che1 and Bev + Che2/3 arms, respectively). And the detailed Bevcontaining chemotherapy regimens were listed in Table 1 . Because of the unavailability of TKIs targeting to the other driver genes except for EGFR/ALK/ROS1 in China, here we grouped these driver genes as the wild type.

\section{Treatment efficacy}

To find the difference of responses among patients treated with Bev introduced in different lines combined with chemotherapy, the ORR and DCR were calculated (Table 2). ORR and DCR in all patients were $34.0 \%$ and $94.8 \%$, respectively. Sixty-six patients $(34.0 \%)$ had partial response as their greatest response, 118 patients $(60.8 \%)$ had stable disease. No patient experienced a complete response. Subgroup analysis showed there was no statistical difference in ORR between patients treated with $\mathrm{Bev}+\mathrm{Che} 1$ versus Bev + Che $2 / 3$ (36.3\% vs. $31.5 \%, \mathrm{P}=0.485)$. Whereas, the DCR of Bev + Che1 was significantly higher than Bev + Che2/3 (99.0\% vs. 90.2\%, $\mathrm{P}=0.007)$. The evaluation of efficacy between Bev administered $>6$, and $\mathrm{u} 6$ course groups showed the DCR of $>6$ courses group was significantly higher than e6 courses group ( $100 \%$ vs. $91.7 \%, \mathrm{P}=0.014)$, which showed a benefit of patients under long-course Bev treatment.

\section{Analyses of survival outcome and the predictors}

Univariate and multivariate analyses were performed to find the independent predictors of PFS (Table 3). Univariate analysis showed that lines of bevacizumab (Bev + Che1 vs. Bev + Che2/3; $\mathrm{P}=0.001)$, ECOG PS $(\geq 2$ vs. $<2 ; \mathrm{P}<0.001)$, stages number of metastatic sites ( $\geq 3$ vs. $<3 ; \mathrm{P}=0.044)$, bone metastasis (yes vs. no; $\mathrm{P}=0.018$ ), previous TKIs therapy (yes vs. no; $\mathrm{P}=0.006$ ), previous anti-PD-L1/PD-1 therapy (yes vs. no; $\mathrm{P}=0.039)$ and courses of bevacizumab ( $>6$ vs. $\leq 6$; $\mathrm{P}=0.006)$ were related to the PFS performance. Meanwhile, prior anti-angiogenesis therapy showed no impact on the 


\section{Page 4 of 15}

Long et al. The timing and courses of bevacizumab added to chemotherapy

Table 1 Patient baseline characteristics ( $\mathrm{n}=194)$

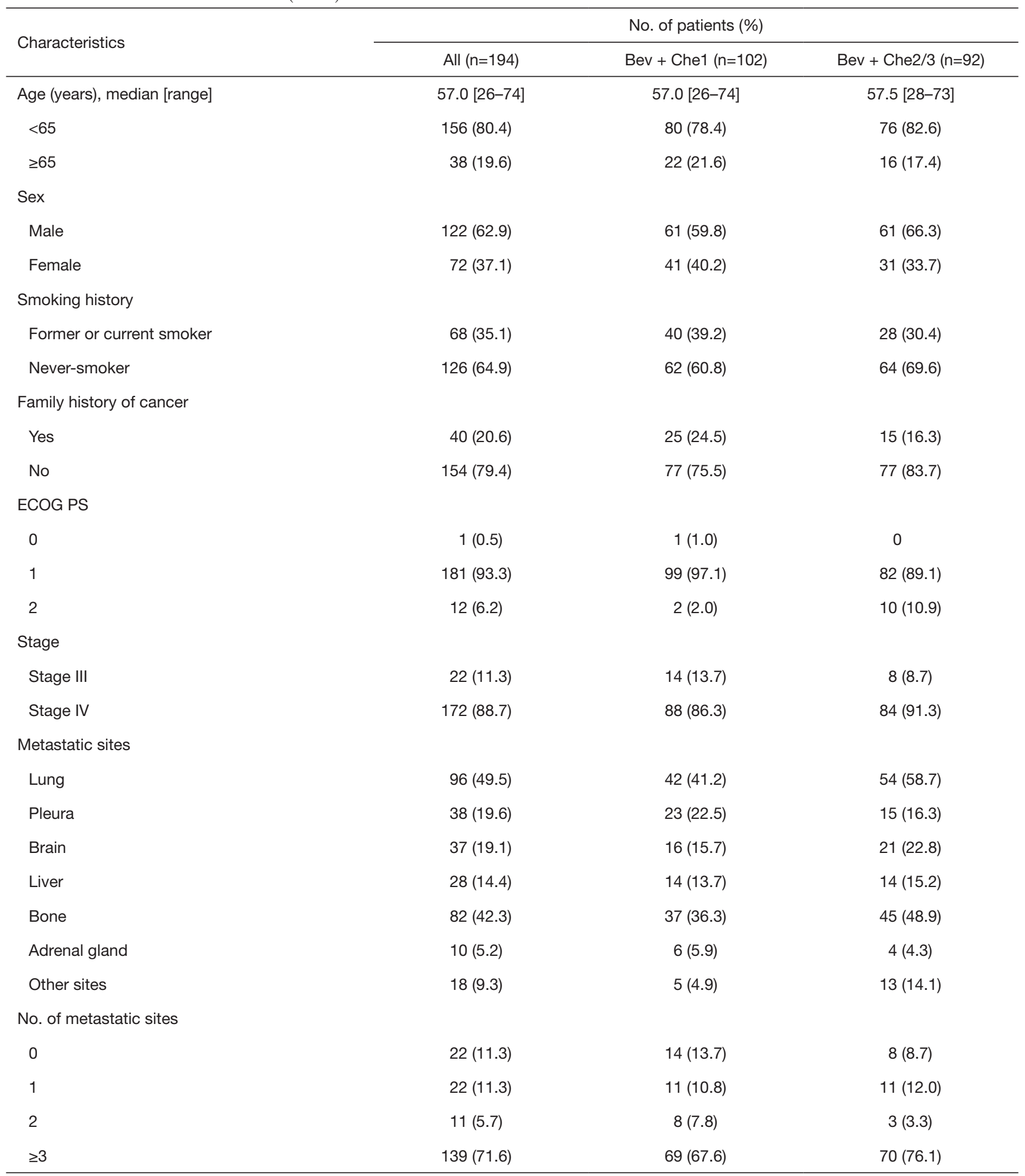

Table 1 (continued) 
Table 1 (continued)

\begin{tabular}{|c|c|c|c|}
\hline Characteristics & \multicolumn{3}{|c|}{ No. of patients (\%) } \\
\hline 1 & $102(52.6)$ & $102(100.0)$ & 0 \\
\hline 2 & $58(29.9)$ & 0 & $58(63.0)$ \\
\hline \multicolumn{4}{|l|}{ Driver gene status } \\
\hline \multicolumn{4}{|l|}{ Driver gene mutant } \\
\hline EGFR & $77(39.4)$ & $32(31.4)$ & $45(48.9)$ \\
\hline$A L K$ & $2(1.0)$ & $2(2.0)$ & 0 \\
\hline Unknown & $15(7.7)$ & $10(9.8)$ & $5(5.4)$ \\
\hline \multicolumn{4}{|c|}{ Bev-containing chemotherapy regimen } \\
\hline Pemetrexed and platinum & $107(55.2)$ & $91(89.2)$ & $16(17.4)$ \\
\hline Paclitaxel and platinum & $54(27.8)$ & $4(3.9)$ & $50(54.3)$ \\
\hline Docetaxel and platinum & $4(2.1)$ & $1(1.0)$ & $3(3.3)$ \\
\hline Gemcitabine and platinum & $9(4.6)$ & $1(1.0)$ & $8(8.7)$ \\
\hline Vinorelbine and platinum & $1(0.5)$ & 0 & $1(1.1)$ \\
\hline \multicolumn{4}{|l|}{ Prior TKIs therapy } \\
\hline Yes & $37(19.1)$ & 0 & $37(40.2)$ \\
\hline No & $157(80.9)$ & $102(100.0)$ & $55(59.8)$ \\
\hline \multicolumn{4}{|l|}{ Prior anti-angiogenesis therapy } \\
\hline Yes & $5(2.6)$ & 0 & $5(5.4)$ \\
\hline No & $189(97.4)$ & $102(100.0)$ & $87(94.6)$ \\
\hline \multicolumn{4}{|l|}{ Prior anti-PD-L1/PD-1 therapy } \\
\hline Yes & $13(6.7)$ & 0 & $13(14.1)$ \\
\hline No & $181(93.3)$ & $102(100.0)$ & 79 (85.9) \\
\hline
\end{tabular}

\#, Prior anti-angiogenesis therapy included Endostar $(n=2)$, Anlotinib $(n=2)$, and Fruquintinib $(n=1)$. Bev + Che1, Bevacizumab added to the first-line chemotherapy; Bev + Che2/3, Bevacizumab added to the second-/third-/later-line line chemotherapy. 
Table 2 Response evaluation of patients separated into distinct groups ( $\mathrm{n}=194)$

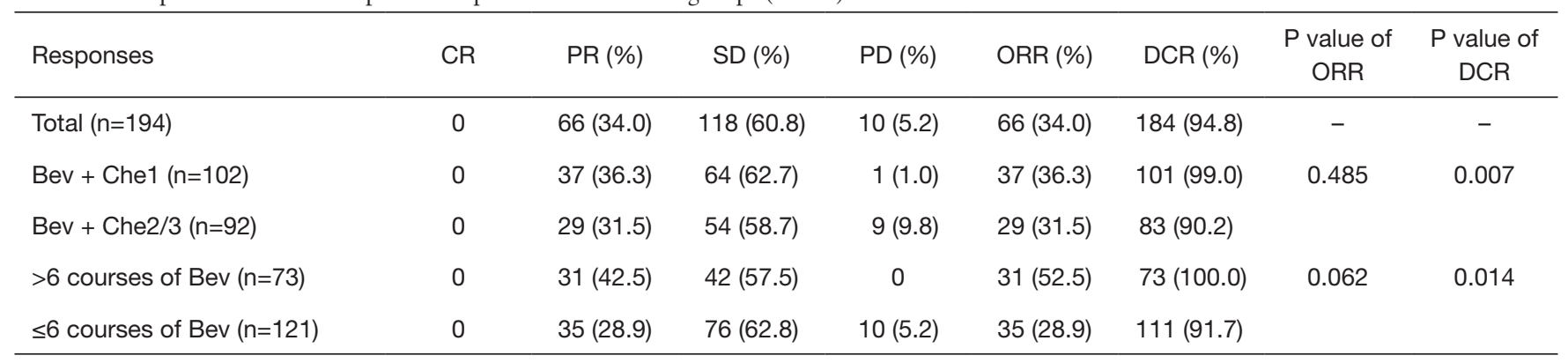

CR, complete response; PR, partial response; SD, stable disease; PD, progressive disease; ORR, objective response rate; DCR, disease control rate.

Table 3 Univariate and multivariate analysis of PFS in all patients $(\mathrm{n}=194)$

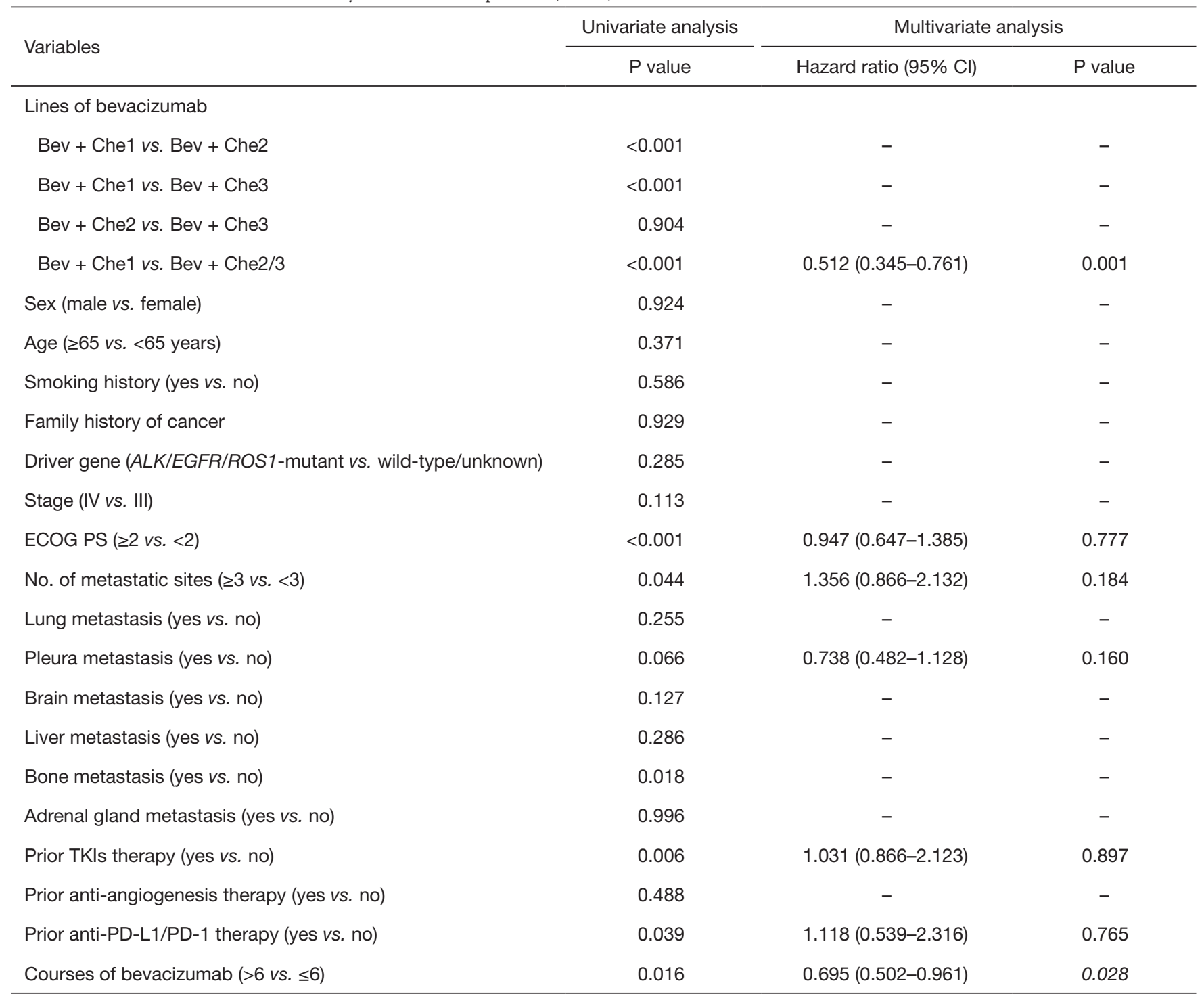

PFS, progression-free survival. 

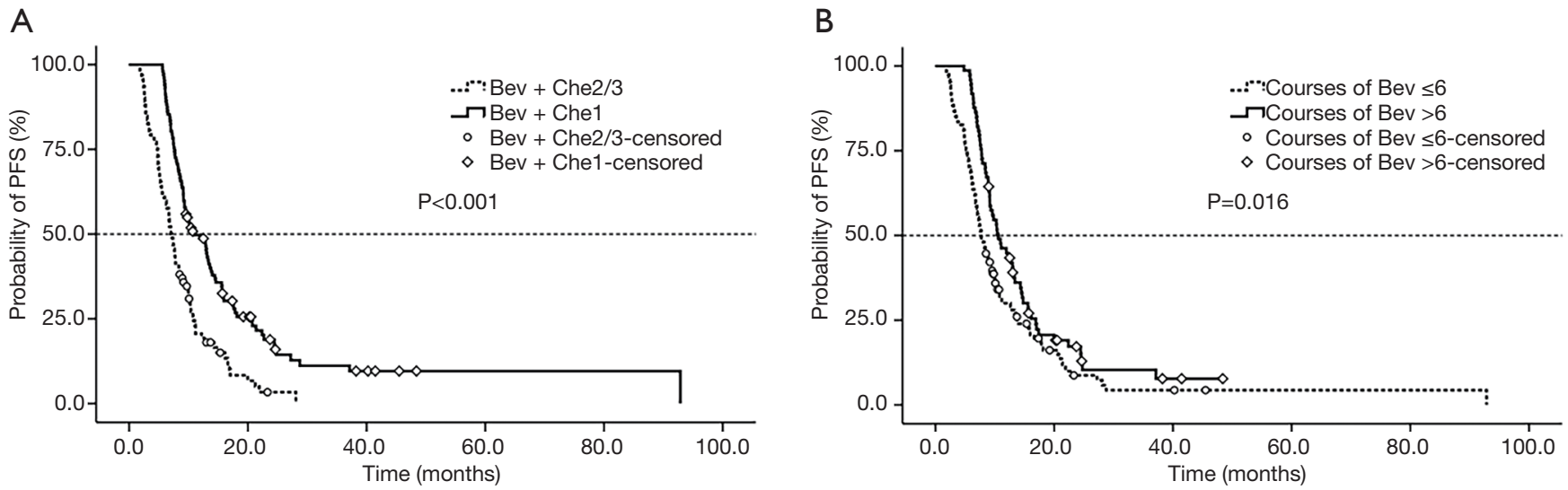

Figure 1 Kaplan-Meier PFS curve analysis of (A) the timing of Bev added to chemotherapy (Bev + Che1 vs. Bev + Che2/3); and (B) courses of bevacizumab ( $>6$ vs. $\leq 6)$. PFS, progression-free survival.

PFS, which showed a maintained response of Bev treatment in patients treated with other anti-angiogenesis drugs. Variables with $\mathrm{P}$ value $<0.1$ in the univariate analysis were included in a multivariate analysis. Among variables finally included in the regression equation by multivariate analysis, there was no significant difference in prior TKIs therapy and anti-PD-(L)1 therapy. These results showed that prior treatment of TKI, anti-angiogenesis, and anti-PD-(L)1 therapy may have no impact on the efficacy of Bev plus chemotherapy. As expected, multivariate analysis found the lines and courses of Bev as significant independent predictive factors. Bev administered at the first-line chemotherapy (Bev + Che1) showed significantly longer PFS compared to the second-line (Bev + Che2) and third-/ later-line (Bev + Che3), but there was no difference between Bev + Che 2 and Bev + Che3 cohorts (Table 3). Meanwhile, patients treated with Bev for $>6$ courses showed significantly longer PFS. We then tested the PFS via Kaplan-Meier curve analysis of the independent predictors, treatment lines, and courses. The PFS was significantly higher in the Bev + Che1 group compared to the Bev + Che2/3 group (mPFS: 10.9 vs. 7.1 months; $\mathrm{P}<0.001$ ) (Figure $1 A$ ). And the analysis of PFS between courses $>6$ and $\leq 6$ groups showed a consistent result (mPFS: 10.6 vs. 7.7 months; $\mathrm{P}=0.016$ ) (Figure 1B). Additionally, detailed univariate analyses of the PFS in all patients were shown in Table S1.

As the treatment lines and courses influence PFS in the population, we then perform clinical subgroup analysis to find factors related to PFS. A forest plot showed that people older than 65 years might not benefit more from Bev added to the first-line chemotherapy, compared to second or later line use $(\mathrm{HR}=0.871,95 \% \mathrm{CI}: 0.419-1.813$; interaction
$\mathrm{P}=0.042$ ) (Figure 2). Also, no significant beneficial effect of Bev plus the first-line chemotherapy was observed in ECOG PS $\geq 2$ group (HR $=0.021,95 \%$ CI: 0.000-6.541; $\mathrm{P}=0.043)$, which may occur because of the small number of patients with PS n2 (n=12, 6.2\%) (Figure 2). Although adrenal gland metastasis did not relate to the PFS with Bev plus chemotherapy in different lines, patients with adrenal gland metastasis showed a higher possibility of PFS benefit from Bev plus the first-line chemotherapy ( $\mathrm{HR}=0.075,95 \%$ CI: 0.008-0.704; interaction $\mathrm{P}=0.044$ ) (Figure 2). As for the treatment courses, a forest plot showed that only ECOG PS $\geq 2$ group had no significant PFS benefit with Bev treatment $>6$ courses $(\mathrm{HR}=0.021$, 95\% CI: 0.000-6.541; P=0.014) which may also be caused by the small sample size (Figure 3).

Given that maintenance therapy is associated with improved survival, we then compared the PFS of patients treated Bev with and without chemotherapy in $>6$ courses Bev cohort. And the results showed no significant difference between the two groups $(\mathrm{P}=0.354)$ (Figure 4), showing that Bev monotherapy could be used instead of Bev plus chemotherapy to reduce the side effect of chemotherapy for patients in maintenance therapy.

Next, the univariate and multivariate analyses were performed to determine the predictor of OS (Table 4). In univariate analysis, the lines of bevacizumab administered (Bev + Che1 vs. Bev + Che2/3; $\mathrm{P}<0.001)$, stage (IV vs. III; $\mathrm{P}=0.031)$, ECOG PS ( $\geq 2$ vs. $<2 ; \mathrm{P}<0.001)$, number of metastatic sites ( $\geq 3$ vs. $<3$; $\mathrm{P}=0.005$ ), liver metastasis (yes vs. no; $\mathrm{P}=0.006$ ), bone metastasis (yes vs. no; $\mathrm{P}<0.001$ ), previous TKIs therapy (yes vs. no; $\mathrm{P}=0.003$ ) and courses of bevacizumab ( $>6 v s . \leq 6 ; \mathrm{P}=0.006)$ were significantly related to OS (Table 4). In Multivariate analysis, Bev plus 


\begin{tabular}{|c|c|c|c|c|}
\hline Subgroup & & Hazard ratio $(95 \% \mathrm{Cl})$ & & Interaction P \\
\hline Overall & $\mapsto$ & & & \\
\hline Sex & & & & 0.118 \\
\hline Male & $\mapsto$ & & $0.536(0.362-0.795)$ & \\
\hline Female & $\mapsto$ & & $0.325(0.192-0.551)$ & \\
\hline Age & & & & 0.042 \\
\hline$\geq 65$ years & $\longmapsto$ & $\longrightarrow$ & $0.871(0.419-1.813)$ & \\
\hline$<65$ years & $\mapsto$ & & $0.397(0.279-0.564)$ & \\
\hline Smoking history & & & & 0.162 \\
\hline Former or current smoker & $\longmapsto$ & & $0.605(0.361-1.015)$ & \\
\hline Never-smoker & $\mapsto$ & & $0.394(0.264-0.589)$ & \\
\hline Family history of cancer & & & & 0.313 \\
\hline Yes & $\longmapsto$ & & $0.350(0.174-0.705)$ & \\
\hline No & $\mapsto$ & & $0.490(0.345-0.696)$ & \\
\hline Driver gene status & & & & 0.869 \\
\hline ALK/EGFR/ROS1-mutant & $\longmapsto$ & & $0.467(0.291-0.751)$ & \\
\hline Wild-type & $\mapsto$ & & $0.472(0.310-0.719)$ & \\
\hline Stage & & & & 0.837 \\
\hline III & $\longmapsto$ & $\longrightarrow$ & $0.472(0.340-0.656)$ & \\
\hline IV & $\mapsto$ & & $0.443(0.152-1.290)$ & \\
\hline ECOG PS & & & & 0.043 \\
\hline$\geq 2$ & 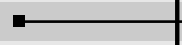 & $\longrightarrow$ & $0.021(0.000-6.541)$ & \\
\hline$<2$ & $\mapsto$ & & $0.497(0.497-0.687)$ & \\
\hline No. of metastatic sites & & & & 0.550 \\
\hline$\geq 3$ & $\longmapsto$ & $\longrightarrow$ & $0.482(0.192-1.211)$ & \\
\hline$<3$ & $\longmapsto$ & $\longrightarrow$ & $0.443(0.152-1.290)$ & \\
\hline Lung metastasis & & & & 0.067 \\
\hline Yes & $\mapsto$ & & $0.393(0.246-0.629)$ & \\
\hline No & $\longmapsto$ & & $0.595(0.383-0.926)$ & \\
\hline Pleura metastasis & & & & 0.186 \\
\hline Yes & $\mapsto$ & & $0.280(0.127-0.616)$ & \\
\hline No & $\mapsto$ & & $0.518(0.368-0.729)$ & \\
\hline Brain metastasis & & & & 0.156 \\
\hline Yes & $\longmapsto$ & $\longrightarrow$ & $0.696(0.348-1.392)$ & \\
\hline No & $\mapsto$ & & $0.414(0.291-0.588)$ & \\
\hline Liver metastasis & & & & 0.261 \\
\hline Yes & $\mapsto$ & & $0.258(0.102-0.653)$ & \\
\hline No & $\mapsto$ & & $0.480(0.342-0.673)$ & \\
\hline Bone metastasis & & & & 0.119 \\
\hline Yes & $\longmapsto$ & & $0.618(0.387-0.987)$ & \\
\hline No & $\mapsto$ & & $0.384(0.251-0.588)$ & \\
\hline Adrenal gland & & & & 0.044 \\
\hline Yes & $\longrightarrow$ & & $0.075(0.008-0.704)$ & \\
\hline No & $\mapsto$ & & $0.477(0.347-0.657)$ & \\
\hline Courses of bevacizumab & & & & 0.172 \\
\hline$>6$ & $\longmapsto$ & & $0.589(0.345-1.005)$ & \\
\hline$\leq 6$ & $\mapsto$ & & $0.433(0.292-0.642)$ & \\
\hline Previous TKIs therapy & & & & 0.794 \\
\hline Yes & $\longrightarrow$ & 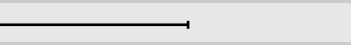 & $0.673(0.159-2.844)$ & \\
\hline No & $\mapsto$ & & $0.453(0.314-0.653)$ & \\
\hline & $0 \quad 0.20 .40 .60 .81$. & $\underset{01.21 .41 .61 .82 .0}{\longrightarrow}$ & & \\
\hline & + Bev1 better & Che + Bev2/3 better & & \\
\hline
\end{tabular}

Figure 2 Forest plot of treatment to a subgroup analysis of PFS. Bev combined with first-line, and second-/third-/later-line chemotherapy was shown as Che + Bev1 and Che + Bev2/3, respectively. PFS, progression-free survival. 


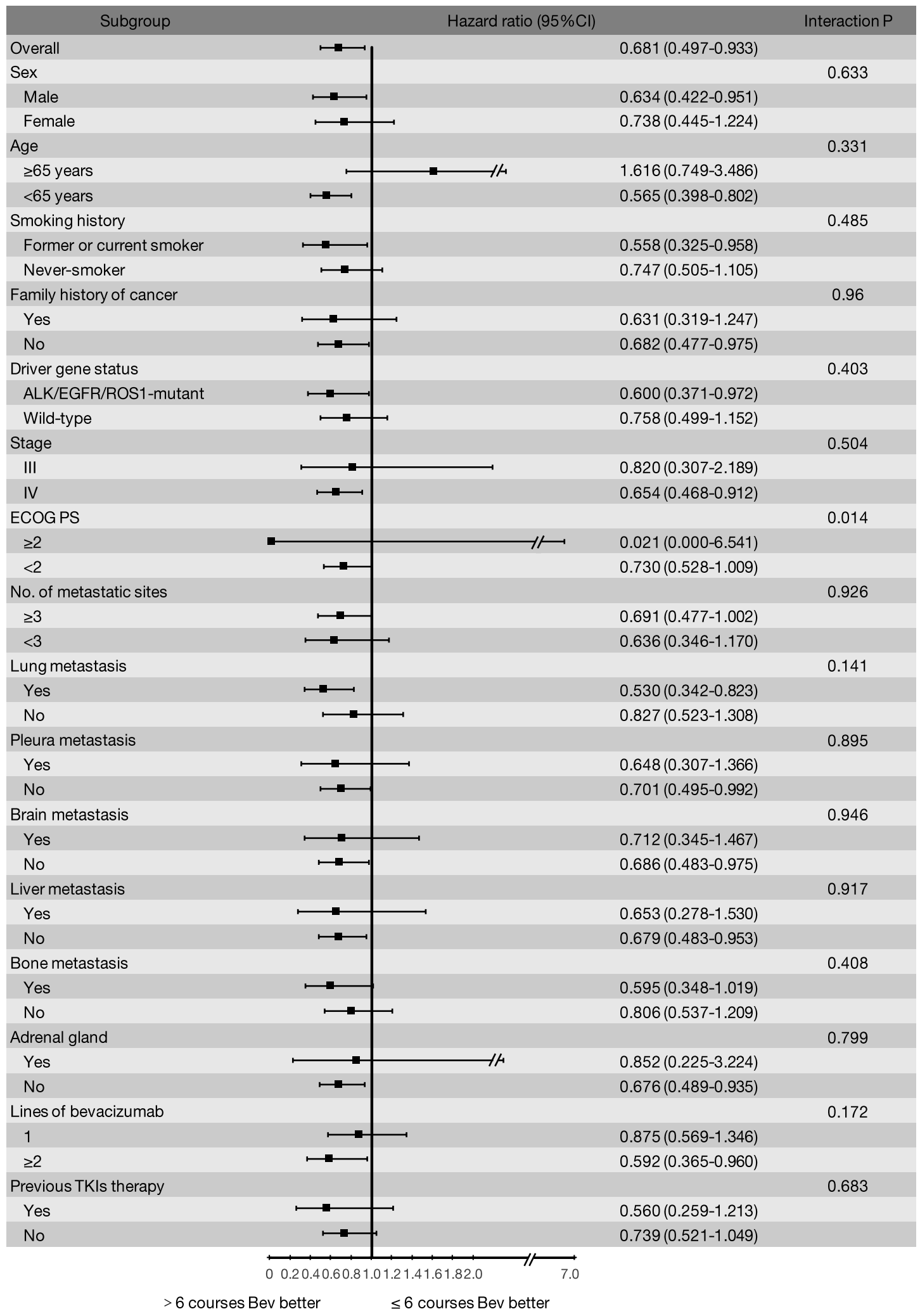

Figure 3 Forest plot of courses of Bevacizumab ( $>6$ vs. $\leq 6)$ added to chemotherapy to subgroup analysis of PFS. PFS, progression-free survival. 
Page 10 of 15

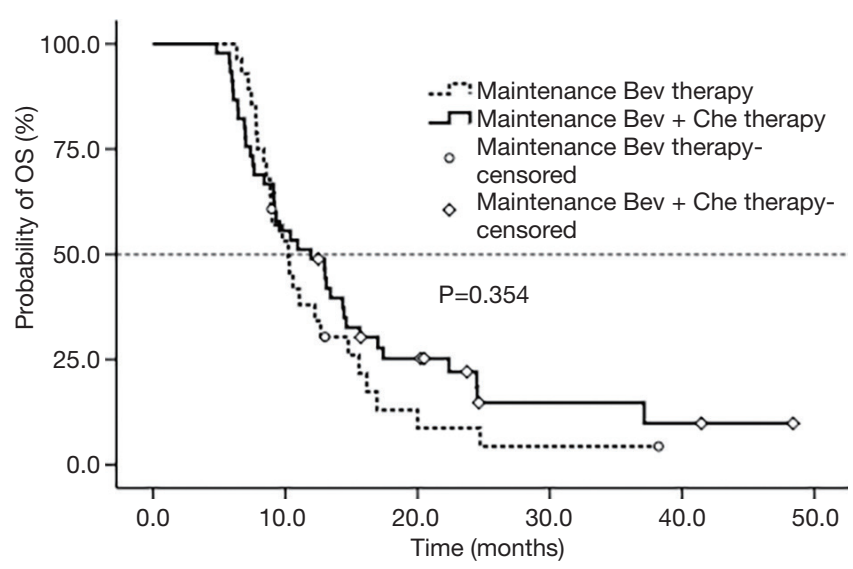

Figure 4 Kaplan-Meier PFS curve analysis of Bev single-agent vs. Bev plus chemotherapy of maintenance therapy in patients received $>6$ courses of Bev. PFS, progression-free survival.

the first-line chemotherapy predicted significantly longer OS compared to second-/third-/later-line (HR $=0.347$, 95\% CI: 0.216-0.558; P<0.001) treatment, consistent with PFS results (Table 4). And the Kaplan-Meier curve was then analyzed. The OS was significantly higher in the Bev + Che1 group compared to the $\mathrm{Bev}+\mathrm{Che} 2 / 3$ group (mOS: $29.0 \mathrm{vs}$. 13.3 months; $\mathrm{P}<0.001)$ (Figure $5 A$ ). The other independent predictive factor was the number of metastatic sites (HR $=1.689,95 \%$ CI: $1.005-2.835 ; \mathrm{P}=0.048$ ) (Table 4), and the analysis of OS showed that patients with metastatic sites $\geq 3$ had shorter OS (mOS: 17.4 vs. 20.0 months; $\mathrm{P}=0.005$ ) compared to $<3$ group (Figure $5 B$ ). Whereas, no significant predictive capacity on OS was found with treatment courses $>6$ (Table 4). In addition, detailed univariate analyses of the OS in all patients was shown in Table $S 2$.

\section{Safety with therapeutic regimens}

A total 91 patients (46.9\%) experienced any grade adverse events (AEs), while 20 patients $(10.3 \%)$ had grade 3 or higher toxicity (Table 5). We focus on the most commonly reported AEs during bevacizumab-containing chemotherapy treatment, including leukopenia (66/194, 34.0\%), neutropenia $(65 / 194,33.5 \%)$, prolonged activated partial thromboplastin time (14/194, 7.3\%), hypertension (49/194, $25.3 \%)$, proteinuria $(30 / 194,15.5 \%)$ and thrombocytopenia (11/194, 5.6\%) (Table 5). Besides, the grade 3-5 AEs the patients suffered included leukopenia $(n=9,4.6 \%)$, neutropenia $(\mathrm{n}=15,7.7 \%)$, thrombocytopenia $(\mathrm{n}=2,1.0 \%)$, elevated blood total bilirubin $(n=1,0.5 \%)$, proteinuria $(\mathrm{n}=1,0.5 \%)$ and hypertension $(\mathrm{n}=2,1.0 \%)$. Withdraw of bevacizumab happened in 5 patients during their treatment, 2 for grade 2 phlebothrombosis, 1 for grade 4 elevated transaminases, 1 for grade 3 proteinuria, and 1 for grade 4 thrombocytopenia accompanied by skin hemorrhage. There were no unreported safety signals observed in all enrolled patients. In addition, the detailed AEs categorized by driver gene status were listed in Table S3.

\section{Discussion}

Bev combined with chemotherapy has been recommended as the first-line agent in advanced NSCLC with no driver mutations. However, the efficacy and safety of Bev administration in second-/later-line chemotherapy, in EGFR/ALK/ROS1-mutant NSCLC, the optimal timing and courses added to chemotherapy, and the most beneficial maintenance therapy paradigm was still under investigation. Our study shows Bev added to the first-line chemotherapy, and $>6$ courses of Bev achieved prolonged PFS, which were verified in each subgroup, suggesting that patients with EGFR/ALK/ROS1-mutant NSCLC can also benefit from the regimen. And the single-agent Bev was efficacious as maintenance therapy. Besides, Bev, in combination with the first-line chemotherapy, was proven beneficial for OS. Last, the regiment is well-tolerated.

In a retrospective study, including 62 non-squamous NSCLC patients treated with Bev plus chemotherapy at second/later-line, the mPFS and mOS were 6.4 and 20.4 months, respectively (16). In our study, Bev combined with chemotherapy as second-line or later-line treatment achieved mPFS of 7.1 months, and mOS of 13.3 months. We identified a significantly prolonged mPFS (10.9 months) and mOS (29.0 months) in patients treated with Bev plus chemotherapy in the first-line therapy, compared to that in second-line or later-line treatment in our data.

Besides, the two independent factors associated with PFS with Bev plus chemotherapy were revealed in our studylines of $\mathrm{Bev}(\mathrm{Bev}+\mathrm{Che} 1$ vs. $\mathrm{Bev}+\mathrm{Che} 2 / 3)$ and courses of bevacizumab ( $>6 v s . \leq 6)$, which was consistent with the differences of DCR in the corresponding groups and can independently predict the PFS benefit regardless of driver gene status, previous targeted therapy, and the other factors studied in our study, providing valuable information for therapeutic decision-making in clinical practice. It has been reported that the wild-type EGFR was a predictor of poor OS in NSCLC patients treated with Bev plus chemotherapy (17). However, the status of EGFR and prior TKI had no 
Table 4 Univariate and multivariate analysis of OS in all patients $(n=194)$

\begin{tabular}{|c|c|c|c|}
\hline Variables & $\frac{\text { Univariate analysis }}{\mathrm{P} \text { value }}$ & \multicolumn{2}{|c|}{ Multivariate analysis } \\
\hline \multicolumn{4}{|l|}{ Lines of bevacizumab } \\
\hline Bev + Che1 vs. Bev + Che2 & $<0.001$ & - & - \\
\hline Bev + Che1 vs. Bev + Che3 & $<0.001$ & - & - \\
\hline $\mathrm{Bev}+\mathrm{Che} 1$ vs. Bev $+\mathrm{Che} 2 / 3$ & $<0.001$ & $0.347(0.216-0.558)$ & $<0.001$ \\
\hline Sex (male vs. female) & 0.064 & $1.175(0.716-1.931)$ & 0.522 \\
\hline Age ( $\geq 65$ vs. $<65$ years) & 0.480 & - & - \\
\hline Smoking history (yes vs. no) & 0.063 & $0.963(0.574-1.617)$ & 0.888 \\
\hline Stage (IV vs. III) & 0.031 & $1.142(0.421-3.099)$ & 0.794 \\
\hline ECOG PS ( $\geq 2$ vs. <2) & $<0.001$ & - & - \\
\hline No. of metastatic sites ( $\geq 3$ vs. $<3$ ) & 0.005 & $1.689(1.005-2.835)$ & 0.048 \\
\hline Lung metastasis (yes vs. no) & 0.271 & - & - \\
\hline Pleura metastasis (yes vs. no) & 0.065 & $0.613(0.351-1.068)$ & 0.084 \\
\hline Brain metastasis (yes vs. no) & 0.550 & - & - \\
\hline Liver metastasis (yes vs. no) & 0.006 & - & - \\
\hline Bone metastasis (yes vs. no) & $<0.001$ & - & - \\
\hline
\end{tabular}

OS, overall survival.

independent impact on the survival of our data. Further, Bev added to chemotherapy in the first-line setting was identified as a favorable independent factor for OS in this study, which again further verified the necessity to introduce Bev into chemotherapy as early as possible.

Maintenance therapy after the Bev combined with chemotherapy also is still a concern in clinical practice. A clinical trial recently performed using Bev vs. Bev plus chemotherapy as maintenance therapy after $4 \mathrm{Bev}$ plus chemotherapy as the first-line treatment in patients with advanced non-squamous NSCLC (18). The results showed that patients treated with Bev plus chemotherapy as maintenance therapy had a significantly longer mPFS (10.2 vs. 6.6 months, $\mathrm{P}<0.001)$. Another clinical trial focused on the same issue also reported a prolonged PFS with the combination as maintenance therapy, while no OS benefit was observed, showing that the combination as maintenance therapy is not recommended (19). In our realworld study, we found that in patients treated with Bev for over 6 courses, no difference of the PFS was found between Bev single-agent and Bev plus chemotherapy. The results controversial to the two clinical trials may attribute to two explanations.

On the one hand, patients receiving $>6$ courses of 
Page 12 of 15

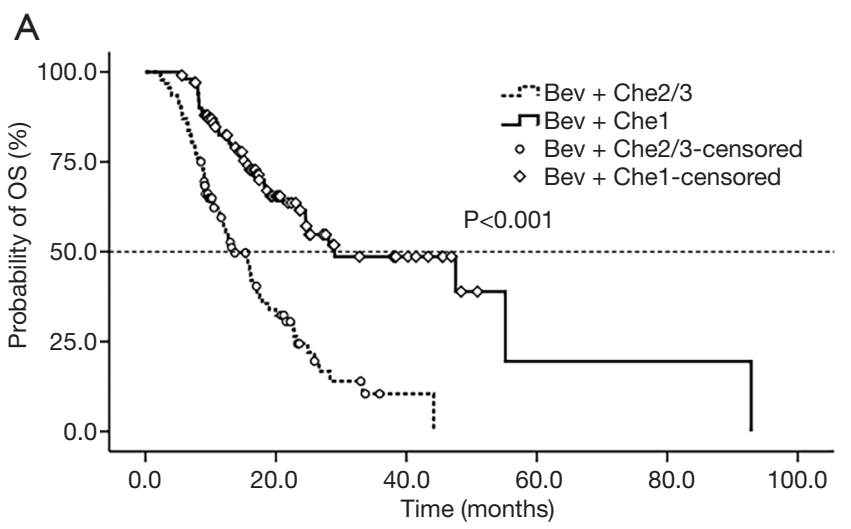

Long et al. The timing and courses of bevacizumab added to chemotherapy

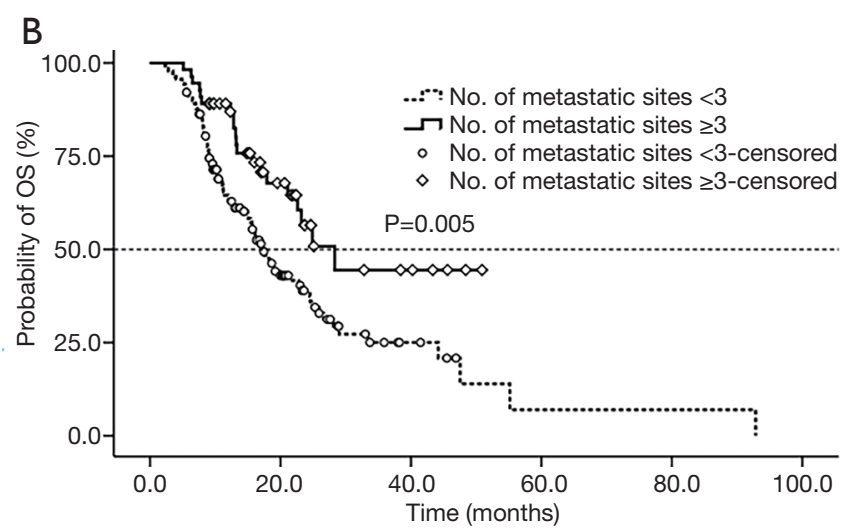

Figure 5 Kaplan-Meier OS curve analysis of (A) the timing of Bev added to chemotherapy (Bev + Che1 vs. Bev + Che2/3); and (B) metastatic sites $(\geq 3$ vs. $<3)$. OS, overall survival.

Table 5 Adverse events reported $(\mathrm{n}=194)$

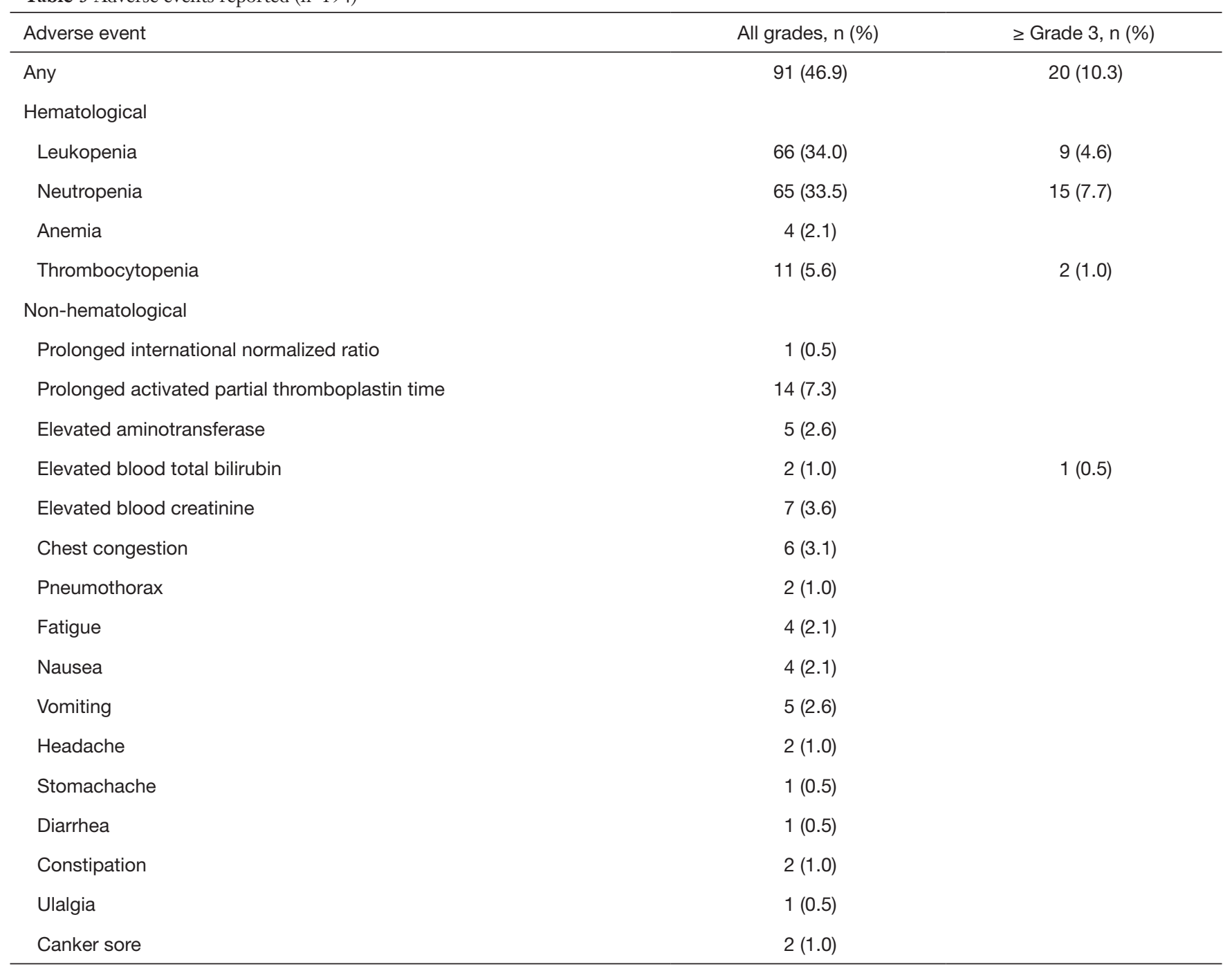

Table 5 (continued) 
Table 5 (continued)

\begin{tabular}{lc}
\hline Adverse event & All grades, $\mathrm{n}(\%)$ \\
\hline Unconsciousness & $1(0.5)$ \\
Allergy & $2(1.0)$ \\
Bev-associated & \\
Hypertension & $49(25.3)$ \\
Proteinuria & $30(15.5)$ \\
Thrombosis & $3(1.5)$ \\
Epistaxis & $2(1.0)$ \\
Gingival hemorrhage & $3(1.5)$ \\
Skin hemorrhage & $2(1.0)$ \\
Hematochezia & $1(0.5)$ \\
Fecal occult blood positive & $3(1.5)$ \\
Intratumoral hemorrhage & $1(0.5)$ \\
\hline
\end{tabular}

Bev-those receiving 6 courses of Bev plus induction chemotherapy, compared with those receiving 4 courses of the regiment, have higher ORR, suggesting they are more sensitive to this regimen and have a much better prognosis of PFS. Hence, the role of chemotherapy in maintenance therapy may not be indispensable to improve the PFS. On the other, we included patients received second- and laterline chemotherapy plus Bev. All these integrated results showed that the administration of Bev combined with firstline chemotherapy, compared to the later-line, and followed by Bev single-agent maintenance therapy, compared to the combination therapy, may achieve longer survival with improved quality of life. This hypothesis should be further tested.

So far, few retrospective studies focused on the roles of the timing of Bev added to chemotherapy, the courses of Bev, and the regimen of subsequent maintenance therapy play on the survival with Bev plus chemotherapy. Our study not only clarified the predictors of PFS with Bev-containing chemotherapy but also further verified their impact in every subgroup, which supplied more substantial information to support these findings.

There were some limitations in our study, including the selection bias, the immature of OS data, and the limited sample size presented in our study. The confirmation of whether lines of bevacizumab contributed to OS difference with larger sample size and long-term follow-up is needed.

\section{Conclusions}

Bev added to the first-line chemotherapy, and $>6$ courses of Bev serve as favorable predictors for PFS. And the singleagent $\mathrm{Bev}$ is efficacious as maintenance therapy. Last, Bev, in combination with the first-line chemotherapy, is also proven more beneficial for OS than that with $2^{\text {nd }}$-line or $3^{\text {rd }}$ line chemo and is well-tolerated.

\section{Acknowledgments}

Funding: The Shanghai Science and Technology Committee Natural Science Foundation supported this study (Contract grant numbers: 19ZR1410400).

\section{Footnote}

Reporting Checklist: The authors have completed the STROBE reporting checklist. Available at http://dx.doi. org/10.21037/atm-20-6327

Data Sharing Statement: Available at http://dx.doi. org/10.21037/atm-20-6327

Conflicts of Interest: All authors have completed the ICMJE uniform disclosure form (available at http://dx.doi. org/10.21037/atm-20-6327). The authors have no conflicts of interest to declare. 
Ethical Statement: The authors are accountable for all aspects of the work in ensuring that questions related to the accuracy or integrity of any part of the work are appropriately investigated and resolved. All procedures performed in this study involving human participants were in accordance with the Declaration of Helsinki (as revised in 2013). The institutional review board approved this study of the Fudan University of Shanghai Cancer Center. Individual consent for this retrospective analysis was waived.

Open Access Statement: This is an Open Access article distributed in accordance with the Creative Commons Attribution-NonCommercial-NoDerivs 4.0 International License (CC BY-NC-ND 4.0), which permits the noncommercial replication and distribution of the article with the strict proviso that no changes or edits are made and the original work is properly cited (including links to both the formal publication through the relevant DOI and the license). See: https://creativecommons.org/licenses/by-nc-nd/4.0/.

\section{References}

1. Sateia HF, Choi Y, Stewart RW, et al. Screening for lung cancer. Semin Oncol 2017;44:74-82.

2. Brahmer J, Reckamp KL, Baas P, et al. Nivolumab versus docetaxel in advanced squamous-cell non-small-cell lung cancer. N Engl J Med 2015;373:123-35.

3. Ruiz-Bañobre J, Areses-Manrique MC, MosqueraMartínez J, et al. Evaluation of the lung immune prognostic index in advanced non-small cell lung cancer patients under nivolumab monotherapy. Transl Lung Cancer Res 2019;8:1078-85.

4. Herbst RS, Baas P, Kim DW, et al. Pembrolizumab versus docetaxel for previously treated, PD-L1-positive, advanced non-small-cell lung cancer (KEYNOTE-010): a randomised controlled trial. Lancet 2016;387:1540-50.

5. Shaw AT, Kim DW, Nakagawa K, et al. Crizotinib versus chemotherapy in advanced ALK-positive lung cancer. N Engl J Med 2013;368:2385-94.

6. Hanahan D, Weinberg RA. Hallmarks of cancer: the next generation. Cell 2011;144:646-74.

7. Porta C, Cosmai L, Rizzo M, et al. Single nucleotide polymorphisms in angiogenesis-related genes and outcomes from antiangiogenic therapies in renal cell carcinoma: really a step towards personalized oncology, or not at all? Ann Transl Med 2019;7:S15.
8. Willett CG, Boucher Y, di Tomaso E, et al. Direct evidence that the VEGF-specific antibody bevacizumab has antivascular effects in human rectal cancer. Nat Med 2004;10:145-7.

9. Sandler A, Gray R, Perry MC, et al. Paclitaxel-carboplatin alone or with bevacizumab for non-small-cell lung cancer. N Engl J Med 2006;355:2542-50.

10. Reck M, von Pawel J, Zatloukal P, et al. Phase III trial of cisplatin plus gemcitabine with either placebo or bevacizumab as first-line therapy for nonsquamous non-small-cell lung cancer: AVAil. J Clin Oncol 2009;27:1227-34.

11. Crinò L, Dansin E, Garrido P, et al. Safety and efficacy of first-line bevacizumab-based therapy in advanced nonsquamous non-small-cell lung cancer (SAiL, MO19390): a phase 4 study. Lancet Oncol 2010;11:733-40.

12. Zhou C, Wu YL, Chen G, et al. BEYOND: A Randomized, Double-Blind, Placebo-Controlled, Multicenter, Phase III Study of First-Line Carboplatin/ Paclitaxel Plus Bevacizumab or Placebo in Chinese Patients With Advanced or Recurrent Nonsquamous NonSmall-Cell Lung Cancer. J Clin Oncol 2015;33:2197-204.

13. Lynch TJ Jr, Spigel DR, Brahmer J, et al. Safety and effectiveness of bevacizumab-containing treatment for non-small-cell lung cancer: final results of the ARIES observational cohort study. J Thorac Oncol 2014;9:1332-9.

14. Cortot AB, Audigier-Valette C, Molinier O, et al. Weekly paclitaxel plus bevacizumab versus docetaxel as second- or third-line treatment in advanced non-squamous non-smallcell lung cancer: Results of the IFCT-1103 ULTIMATE study. Eur J Cancer 2020;131:27-36.

15. Hu B, Zhou X, Liu Y, et al. Comparison of chemotherapy plus bevacizumab vs. chemotherapy alone as third-line treatment or beyond for advanced non-small cell lung cancer: A propensity score-matched analysis. Oncol Lett 2018;15:5671-9.

16. Zheng X, Wang H, Zhang G, et al. Efficacy and safety of bevacizumab combined with chemotherapy as secondline or later-line treatment in advanced nonsquamous non-small cell lung cancer. Zhongguo Fei Ai Za Zhi 2018;21:513-8.

17. Huang YC, Shen SM, Liu CY, et al. Impact of prolonged and early bevacizumab treatment on the overall survival of EGFR-mutant and EGFR-wild type nonsquamous nonsmall cell lung cancer. Thorac Cancer 2018;9:1648-55.

18. Barlesi F, Scherpereel A, Rittmeyer A, et al. Randomized 
phase III trial of maintenance bevacizumab with or without pemetrexed after first-line induction with bevacizumab, cisplatin, and pemetrexed in advanced nonsquamous nonsmall-cell lung cancer: AVAPERL (MO22089). J Clin Oncol 2013;31:3004-11.

19. Ramalingam SS, Dahlberg SE, Belani CP, et al.

Cite this article as: Long Q, Feng Y, Liu C, Wu X, Wang H, Yu H, Zhao X, Wang J. The optimal timing and courses of bevacizumab added to chemotherapy for nonsquamous non-small cell lung cancer: revelations from the realworld experience in a single Chinese cancer center. Ann Transl Med 2020;8(20):1311. doi: 10.21037/atm-20-6327
Pemetrexed, bevacizumab, or the combination as maintenance therapy for advanced nonsquamous nonsmall-cell lung cancer: ECOG-ACRIN 5508. J Clin Oncol 2019;37:2360-7.

(English Language Editor: J. Chapnick) 
Table S1 Detailed univariate multivariate analyses of the PFS in all patients $(n=194)$

\begin{tabular}{|c|c|c|}
\hline \multirow{2}{*}{ Variables } & \multicolumn{2}{|l|}{ Univariate analysis } \\
\hline & mPFS (range); HR (95\% Cl) & $P$ value \\
\hline \multicolumn{3}{|l|}{ Lines of bevacizumab } \\
\hline Bev + Che1 vs. Bev + Che2 & $10.9(8.0-13.8)$ vs. 6.8 (5.6-8.0); 0.451 (0.314-0.647) & $<0.001$ \\
\hline Bev + Che 1 vs. Bev + Che3 & $10.9(8.0-13.8)$ vs. 7.2 (6.2-8.2); 0.451 (0.299-0.681) & $<0.001$ \\
\hline Bev + Che2 vs. Bev + Che3 & 6.8 (5.6-8.0) vs. 7.2 (6.2-8.2); $1.028(0.658-1.606)$ & 0.904 \\
\hline Bev + Che 1 vs. Bev + Che2/3 & $10.9(8.0-13.8)$ vs. 7.1 (6.2-7.9); $0.458(0.335-0.626)$ & $<0.001$ \\
\hline Sex (male vs. female) & 9.3 (8.0-10.6) vs. 8.6 (7.2-10.0); 0.985 (0.719-1.348) & 0.924 \\
\hline Age ( $\geq 65$ vs. $<65$ years) & 10.7 (5.1-16.3) vs. 8.8 (7.8-9.9); 0.839 (0.570-1.234) & 0.371 \\
\hline Smoking history (yes vs. no) & 9.0 (7.6-10.4) vs. 9.1 (7.6-10.6); 1.091 (0.797-1.494) & 0.586 \\
\hline Family history of cancer & 9.7 (7.7-11.6) vs. 8.9 (8.0-9.8); 0.983 (0.677-1.428) & 0.929 \\
\hline Driver gene (ALK/EGFR/ROS1-mutant vs. wild-type) & 8.4 (7.2-9.6) vs. 9.7 (8.5-10.9); 1.181 (0.870-1.603) & 0.285 \\
\hline Stage (IV vs. III) & 8.6 (7.5-9.6) vs. 13.0 (10.3-15.6); 1.496 (0.905-2.472) & 0.113 \\
\hline ECOG PS ( $\geq 2$ vs. $<2)$ & 3.1 (1.9-4.3) vs. 9.3 (8.3-10.3); 4.406 (2.424-8.010) & $<0.001$ \\
\hline No. of metastatic sites ( $\geq 3$ vs. $<3$ ) & $8.2(7.0-9.4)$ vs. 10.7 (7.5-14.0); 1.419 (1.007-1.999) & 0.044 \\
\hline Lung metastasis (yes vs. no) & 7.7 (6.3-9.1) vs. 10.3 (8.8-11.8); 1.193 (0.880-1.618) & 0.255 \\
\hline Pleura metastasis (yes vs. no) & 9.6 (3.7-15.4) vs. 8.9 (7.9-9.8); 0.691 (0.465-1.028) & 0.066 \\
\hline Brain metastasis (yes vs. no) & $8.4(6.1-10.7)$ vs. 9.1 (8.1-10.2); 1.232 (0.839-1.808) & 0.127 \\
\hline Liver metastasis (yes vs. no) & $8.4(5.5-11.3)$ vs. 9.1 (8.0-10.3); 1.318 (0.853-2.037) & 0.286 \\
\hline Bone metastasis (yes vs. no) & 7.8 (6.6-8.9) vs. 10.1 (8.7-1.4); 1.450 (1.064-1.975) & 0.018 \\
\hline Adrenal gland metastasis (yes vs. no) & 7.5 (5.1-9.8) vs. 9.1 (8.0-10.2); 1.002 (0.507-1.978) & 0.996 \\
\hline Prior TKIs therapy (yes vs. no) & 7.0 (5.3-8.8) vs. 9.5 (8.5-10.5); 1.681 (1.160-2.438) & 0.006 \\
\hline Prior anti-angiogenesis therapy (yes vs. no) & 7.0 (6.5-7.6) vs. 9.1 (8.1-10.1); 1.369 (0.561-3.340) & 0.488 \\
\hline Prior anti-PD-L1/PD-1 therapy (yes vs. no) & 6.7 (5.8-7.6) vs. 9.3 (8.3-10.3); 1.848 (1.021-3.346) & 0.039 \\
\hline Courses of bevacizumab (>6 vs. $\leq 6$ ) & 10.6 (8.1-13.0) vs. 7.7 (6.7-8.7); 0.681 (0.497-0.933) & 0.016 \\
\hline
\end{tabular}

PFS, progression-free survival.

Table S2 Detailed univariate multivariate analyses of OS in all patients ( $\mathrm{n}=194)$

\begin{tabular}{|c|c|c|}
\hline \multirow{2}{*}{ Variables } & \multicolumn{2}{|l|}{ Univariate analysis } \\
\hline & mOS (range); HR (95\%Cl) & $P$ value \\
\hline \multicolumn{3}{|l|}{ Lines of bevacizumab } \\
\hline Bev + Che1 vs. Bev + Che2 & 29.0 (12.0-46.0) vs. 12.8 (10.6-15.0); 0.338 (0.214-0.534) & $<0.001$ \\
\hline $\mathrm{Bev}+\mathrm{Che} 1$ vs. Bev $+\mathrm{Che} 3$ & 29.0 (12.0-46.0) vs. 15.7 (11.4-20.0); 0.359 (0.215-0.597) & $<0.001$ \\
\hline Bev + Che2 vs. Bev + Che3 & 12.8 (10.6-15.0) vs. 15.7 (11.4-20.0); 1.001 (0.603-1.662) & 0.996 \\
\hline Bev + Che1 vs. Bev + Che2/3 & 29.0 (12.0-46.0) vs. 13.3 (9.8-16.8); 0.341 (0.226-0.514) & $<0.001$ \\
\hline Sex (male vs. female) & 24.8 (21.2-28.4) vs. 17.9 (15.3-20.5); 0.678 (0.448-1.026) & 0.064 \\
\hline Age ( $\geq 65$ vs. $<65$ years) & 18.7 (13.2-24.1) vs. 21.3 (15.5-27.0); 1.194 (0.729-1.956) & 0.480 \\
\hline Smoking history (yes vs. no) & $16.9(11.8-22.0)$ vs. 23.2 (18.2-28.2); 1.458 (0.978-2.175) & 0.063 \\
\hline Family history of cancer & 16.9 (11.5-22.3) vs. 21.2 (16.9-25.6); 1.002 (0.620-1.622) & 0.992 \\
\hline Driver gene (ALK/EGFR/ROS1-mutant vs. wild-type) & 21.2 (13.8-28.7) vs. 18.7 (12.9-24.4); 0.933 (0.630-1.380) & 0.727 \\
\hline Stage (IV vs. III) & $18.7(14.4-23.0)$ vs. unreached; $2.412(1.057-5.506)$ & 0.031 \\
\hline ECOG PS ( $\geq 2$ vs. $<2)$ & 7.7 (5.0-10.4) vs. 22.8 (18.1-27.5); 3.999 (2.114-7.564) & $<0.001$ \\
\hline No. of metastatic sites ( $\geq 3$ vs. $<3$ ) & $17.4(14.7-20.0)$ vs. 28.3 (19.9-36.7); 1.975 (1.210-3.221) & 0.005 \\
\hline Lung metastasis (yes vs. no) & $18.2(15.3-21.1)$ vs. $22.6(17.8-27.4) ; 1.060$ (0.720-1.560) & 0.271 \\
\hline Pleura metastasis (yes vs. no) & 29.0 (17.2-40.8) vs. 17.5 (13.5-21.5); 0.551 (0.322-0.942) & 0.065 \\
\hline Brain metastasis (yes vs. no) & 22.8 (9.8-35.8) vs. 20.0 (15.7-24.3); 0.898 (0.551-1.465) & 0.550 \\
\hline Liver metastasis (yes vs. no) & 12.7 (9.1-16.3) vs. 22.8 (18.2-27.4); 2.049 (1.261-3.330) & 0.006 \\
\hline Bone metastasis (yes vs. no) & 15.6 (12.3-18.9) vs. 28.3 (22.3-34.3); 2.239 (1.513-3.312) & $<0.001$ \\
\hline Adrenal gland metastasis (yes vs. no) & 11.4 (8.2-14.6) vs. 23.2 (18.4-28.0); 1.305 (0.594-2.865) & 0.400 \\
\hline Prior TKIs therapy (yes vs. no) & 13.2 (7.4-19.0) vs. 17.9 (15.3-20.5); 1.944 (1.249-3.027) & 0.003 \\
\hline Prior anti-angiogenesis therapy (yes vs. no) & 21.2 (0-43.4) vs. 20.0 (5.8-24.2); $1.320(0.418-4.169)$ & 0.635 \\
\hline Prior anti-PD-L1/PD-1 therapy (yes vs. no) & $11.4(7.7-15.1)$ vs. $21.1(17.0-25.3) ; 1.460(0.674-3.159)$ & 0.334 \\
\hline Courses of bevacizumab (>6 vs. $\leq 6$ ) & 24.6 (20.0-29.1) vs. 16.9 (14.0-19.8); 0560 (0.369-0.850) & 0.006 \\
\hline
\end{tabular}

OS, overall survival. 
Table S3 Detailed adverse events reported $(n=194)$

\begin{tabular}{|c|c|c|c|c|}
\hline \multirow[b]{2}{*}{ Adverse event } & \multicolumn{2}{|c|}{ All grades, $\mathrm{n}(\%)$} & \multicolumn{2}{|c|}{$\geq$ Grade 3, n (\%) } \\
\hline & $\begin{array}{l}\text { ALK/EGFR/ROS1- } \\
\text { mutant }\end{array}$ & Wild-type/unknown & $\begin{array}{c}\text { ALK/EGFR/ROS1- } \\
\text { mutant }\end{array}$ & Wild-type/unknown \\
\hline Any & $39(20.1)$ & $52(26.8)$ & $4(2.1)$ & $16(8.2)$ \\
\hline \multicolumn{5}{|l|}{ Hematological } \\
\hline Leukopenia & $31(15.9)$ & $35(18.0)$ & 0 & $9(4.6)$ \\
\hline Neutropenia & $25(12.9)$ & $40(20.6)$ & $3(1.5)$ & $12(6.2)$ \\
\hline Anemia & $2(1.0)$ & $2(1.0)$ & & \\
\hline Thrombocytopenia & $6(4.1)$ & $5(2.6)$ & $1(0.5)$ & $1(0.5)$ \\
\hline \multicolumn{5}{|l|}{ Non-hematological } \\
\hline $\begin{array}{l}\text { Prolonged international normalized } \\
\text { ratio }\end{array}$ & 0 & $1(0.5)$ & & \\
\hline $\begin{array}{l}\text { Prolonged activated partial } \\
\text { thromboplastin time }\end{array}$ & $6(3.1)$ & $8(4.1)$ & & \\
\hline Elevated aminotransferase & $3(1.5)$ & $2(1.0)$ & & \\
\hline Elevated blood total bilirubin & 0 & $1(0.5)$ & & $1(0.5)$ \\
\hline Elevated blood creatinine & $2(1.0)$ & $5(2.6)$ & & \\
\hline Chest congestion & $2(1.0)$ & $4(2.1)$ & & \\
\hline Pneumothorax & 1 & & & \\
\hline Fatigue & $2(1.0)$ & $2(1.0)$ & & \\
\hline Nausea & $1(0.5)$ & $3(1.5)$ & & \\
\hline Vomiting & 0 & $5(2.6)$ & & \\
\hline Headache & $1(0.5)$ & $1(0.5)$ & & \\
\hline Stomachache & 0 & $1(0.5)$ & & \\
\hline Diarrhea & $1(0.5)$ & 0 & & \\
\hline Constipation & $1(0.5)$ & $1(0.5)$ & & \\
\hline Ulalgia & 0 & $1(0.5)$ & & \\
\hline Canker sore & $2(1.0)$ & 0 & & \\
\hline Unconsciousness & 0 & $1(0.5)$ & & \\
\hline Allergy & $2(1.0)$ & 0 & & \\
\hline \multicolumn{5}{|l|}{ Bev-associated } \\
\hline Hypertension & $17(8.7)$ & $32(16.5)$ & & $2(1.0)$ \\
\hline Proteinuria & $16(8.2)$ & $14(7.2)$ & & $1(0.5)$ \\
\hline Thrombosis & $1(0.5)$ & $2(1.0)$ & & \\
\hline Epistaxis & $1(0.5)$ & $1(0.5)$ & & \\
\hline Gingival hemorrhage & $2(1.0)$ & $1(0.5)$ & & \\
\hline Skin hemorrhage & $1(0.5)$ & $1(0.5)$ & & \\
\hline Hematochezia & 0 & $1(0.5)$ & & \\
\hline Fecal occult blood positive & $2(1.0)$ & $1(0.5)$ & & \\
\hline Intratumoral hemorrhage & 0 & $1(0.5)$ & & \\
\hline
\end{tabular}

